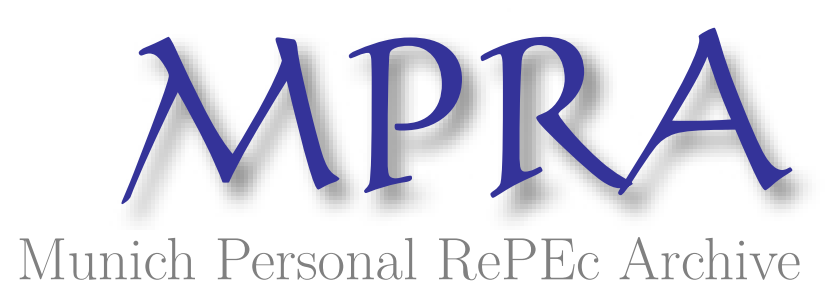

\title{
Input and Output Inventories in the UK
}

Tsoukalas, John

School of Economics, University of Nottingham, UK

April 2009

Online at https://mpra.ub.uni-muenchen.de/18695/

MPRA Paper No. 18695, posted 18 Nov 2009 00:51 UTC 


\title{
Input and Output Inventories in the UK
}

\author{
John D. Tsoukalas \\ School of Economics \\ University of Nottingham \\ University Park \\ Nottingham, NG7 2RD
}

This draft: April 2009

\begin{abstract}
What is the role of inventories in UK manufacturing? We present and estimate a model of inventories that considers separately finished goods and input (i.e. the sum of raw materials and work-in-process) inventories. We estimate structural parameters which allows us to make inferences on the role of inventories in cyclical frequencies. Our results suggest that both types of inventories are used for production level (from demand shocks) and production cost (from cost shocks) smoothing. We identify a small but significant negative relationship between inventories and the real interest rate thus providing support for one of the textbook channels of the monetary policy transmission mechanism. Variance decompositions indicate that technology shocks are the dominant driving factor behind cyclical changes in inventories. These shocks account for over $35 \%$ of the forecast error variance at these frequencies.
\end{abstract}

JEL classification: E22; E23; C11

Key words: Inventories; Linear-quadratic model; Interest rates

Forthcoming in Economica. I would like to thank the editor, Alex Michaelides, and an anonymous referee for helpful comments and suggestions. I would also like to thank Jenni Greenslade, Neal Hatch, Simon Price, Paul Mizen, Hashmat Khan, colleagues and seminar participants at the Bank of England for comments on an earlier draft. I have also benefited from discussions with Scott Schuh on comparing US and UK results and Richard Dennis on technical issues. I am grateful to Richard Barwell, Ronnie Driver and Mike Goldby for providing valuable help with data sources. Email: john.tsoukalas@nottingham.ac.uk 


\section{Introduction}

The importance of inventory movements for the study of aggregate fluctuations has been extensively documented for many OECD countries (see Ramey and West (1999)). In the UK economy movements in inventories account for a relatively large fraction of the cyclical change in GDP and manufacturers stocks play a large role (see Table 1 below). A largely un-noticed fact is the empirical importance of input inventories (defined as the sum of raw materials and work-in-process) in terms of size, volatility and interaction with finished goods inventories (see Table 2 below). As a result input inventories have received very little research effort compared to finished goods inventories. Another important question as noted by Blinder and Maccini (1991) that still remains open is the relationship between the real interest rate and inventories. Business reports and financial media often link higher interest rates to lower inventory investment, but the academic literature until very recently has found little, if any, of a relationship between real interest rates and inventories. The trouble with the lack of evidence is that it undermines one of the traditional channels of monetary policy. According to the monetary policy committee at the Bank of England changes in official rates will affect the interest costs of holding inventories (see Monetary Policy Committee (1999), p.7) and firms will respond by choosing to reduce inventory holdings when confronted with a higher cost of maintaining stocks.

Tables 1 and 2 below document some simple facts that motivate our inquiry. In Table 1 columns 2 and 3 report the contributions of inventory investment (for whole economy and manufacturing stocks respectively) as a percentage in the decline in GDP during post-war UK recessions. Table 1 highlights that inventory liquidation is an important feature of the UK business cycle. Excluding the 1975 recession (where inventories moved countercyclically), all other episodes are associated with stock liquidation.

Table 2 documents the importance of input inventories in UK manufacturing. It demonstrates: (a) that input inventories are nearly twice as large compared to finished goods inventories, (b) investment in input inventories account for over half the total variance of manufacturing inventory investment and (c) a considerable interaction between input and output inventories; as much as one-fourth of the variance of total inventory investment is accounted for by the covariance between input and output inventories. These facts indicate that a useful model of inventory behaviour should consider explicitly input and their interaction with output inventories.

In this paper we develop and estimate a structural inventory model that (i) jointly considers input and output inventory decisions and (ii) can shed light on the relationship between the real interest rate and inventory accumulation. To accomplish these goals we generalize and refine the 
linear-quadratic inventory model developed in Humphreys et al. (2001) (henceforth the inputoutput inventory model) along several dimensions. The refinements we make allow us to gain additional insights. First, we relax the assumption of a constant discount factor which has been used extensively in the empirical inventory literature. This enables us to estimate the effect of the real interest rate on optimal inventory decisions. Second, our methodology allows to separately identify, estimate and assess the importance of a large number of structural shocks that drive the cyclical movements in manufacturing stocks. ${ }^{1}$

In the spirit of its predecessor (the linear-quadratic inventory model of Holt et al. (1960)) the input-output inventory model encompasses all the key motives for holding inventories: allows for the production-smoothing, revenue, but also inter-temporal speculation role for inventories. For example, movements in real input prices (wages, materials input prices and interest rates) confront firms with trade-offs: with more favourable input prices it is cost minimizing to increase stocks today and draw them down in the future when input prices revert to their normal level. The data permit identification of structural parameters that characterize the relative strength of each of the motives above with considerable precision.

There are several important results. We estimate a small but nevertheless significant direct effect of the real interest rate on inventory holdings of the UK manufacturing sector in the short run. We find that both input and output inventories decline when the real interest rate rises. Our results suggest that an interest rate rise of 1 percent translates to a decline in stocks of (approximately) 0.1 percent relative to trend. We call this a direct interest rate effect (or pure interest rate effect) since it indicates the response of inventories to an exogenous shock to the real interest rate holding all other influences constant. This direct effect is driven by an intertemporal substitution channel, whereby a change in the interest rate affects the cost of holding inventories. This finding indicates that manufacturing UK inventories are sensitive to short-run movements in the real interest rate. More importantly, this is consistent with a transmission of monetary policy rate changes to inventories as long as the monetary authority can significantly influence the shortrun real interest rate, which is thought to be the case in the current era of inflation targeting. ${ }^{2}$

\footnotetext{
${ }^{1}$ It is important to note that despite the sector's declining share in the UK economy manufacturing stocks still account for more than one third of total stocks. As of 2006 manufacturing stocks account for 36 percent while distribution (retail and wholesale trade) account for 34 percent and "other" industries for the remaining 27 percent of total stocks. "Other" include industries such as energy, construction, motor trades. Our focus on manufacturing is motivated by two facts. First, input inventories arise predominantly in manufacturing industries. Second, fixed costs of ordering are likely to be very important for understanding the behaviour of retail and wholesale inventories (see e.g. Blinder and Maccini (1991)). However, these fixed costs cannot be easily accommodated by a linear-quadratic framework.

${ }^{2}$ In addition to the direct interest rate effect we identify in this paper there is a broad interest rate channel on inventories through sales. Changes in policy (and real) rates are expected to affect various components of aggregate demand and in turn firm sales and inventories and there is indeed strong evidence for these effects. Moreover, interest rates may impact a further effect through financial variables arising from the
} 
Recent US research by Maccini et al. (2004) uses a similar model to ours and identify a long-run negative relationship between the real interest rate and manufacturing finished goods inventories. Maccini et al. (2004) apply a Markov-switching methodology to identify changes in the real interest rate that are perceived as very persistent by firms in the US manufacturing sector. As the real interest rate moves in and out of high and low regimes, firms respond by cutting down or building up inventories. Thus, similar to this paper, Maccini et al. (2004) resurrect an empirical relationship that has troubled the inventory literature for decades. However, note that contrary to Maccini et al. (2004) we focus on and identify a short-run negative relationship between the real interest rate and inventories. Benito (2005) reaches a similar conclusion using UK firm level data and a measure of financial pressure that varies with the official policy rate. Our finding is also consistent with earlier work by Ramey (1989) who models inventories as factors of production. She estimates a moderate negative short-run relationship between interest rates and input and output inventories in US manufacturing.

Our results also yield important insights about the role of inventories. We find evidence for production level and production cost smoothing. The model's dynamic responses imply that firms satisfy unexpectedly strong demand from finished goods inventories, resulting in a decline of the latter relative to their target (production level smoothing). At the same time when faced with a favourable technology shock that lowers current costs firms build up both types of stocks (production cost smoothing). The convexity of the cost function is directly related to the production smoothing role of inventories and indeed our evidence clearly indicates this to be the case. Finally, we are able to account for the importance of competing shocks that drive inventory movements. Our results indicate that technology shocks are the dominant source of fluctuations in stocks in all cyclical frequencies. Sales and inventory holding cost shocks also play a large role. Last, input price shocks play only a very limited role in driving cyclical fluctuations in stocks.

Recently there has been a resurgence of work on inventories, especially in the US. Maccini and Pagan (2008) explore the importance of inventory swings in the goods-sector cycle and their role in the Great Moderation by developing and estimating a model with input and output inventories for the goods market sector of the US economy very similar to ours. Their conclusions are somewhat surprising given the relatively large amount of work that emphasizes the importance of inventories for business cycles. They identify only a minor contribution of inventories to the length and the amplitude of the average business cycle in the US economy. Further, they suggest that advances in inventory management techniques appear to have contributed very little to the decline of GDP

balance sheet and bank lending channels. For evidence on the latter in the UK see Guariglia (1999) and Guariglia (2000). These mechanisms however are beyond the scope of this paper. 
growth volatility since the early 1980s and hence cannot be a source of the Great Moderation. Iacoviello et al. (2007) develop a model of input and output inventories in a general equilibrium setting and estimate structural parameters that govern inventory behaviour similar to the approach taken in this paper. Iacoviello et al. (2007) find that inventories cannot be the major factor - but have played a role - in the decline of the GDP volatility in the US economy. Finally, Jung and Yun (2005) develop a New-Keynesian model with inventories and seek to address the sluggish behaviour of finished goods inventories following monetary policy shocks. Their findings indicate that a model which combines a low depreciation rate for inventories and adjustment costs for deviations of the sales to stocks ratio from its target, is successful in matching the finished goods inventory dynamics in response to monetary policy shocks. Thus similar to our work, the authors seek to understand the adjustment of inventory stocks following changes in the policy stance. However, they do so from the lens of a New Keynesian general equilibrium model.

There are a handful of papers that study the determinants of UK inventories and are closely related to our study. Hall et al. (1986), Callen et al. (1990) and Cuthbertson and Gasparro (1993) use variants of the linear quadratic inventory model. However neither of these studies decompose inventories by stage of fabrication or estimate structural parameters. ${ }^{3}$ One of the key questions in these earlier studies is the identification of the determinants of the long-run level of stocks, whereas we focus on the cyclical behaviour (and thus abstract from the long run determinants) of stocks and emphasize the interaction of input and output inventories within a structural model.

The rest of the paper proceeds as follows. Section 2 presents a formal description of the model. Section 3 presents and discusses the econometric results along with dynamic properties of the model. Section 4 concludes.

\section{The input-output linear quadratic inventory model with a variable interest rate}

The input-output inventory model (or stage of fabrication inventory model) developed in Humphreys et al. (2001) formalizes the links that exist between different stages of production within and across firms. These links reflect the order, delivery and usage of materials and intermediate goods in the production process on the one hand and the decision to stock the final good as an inventory on the other. Most importantly, these links imply that decisions on output (i.e. finished goods) inventory investment are interrelated with the decisions on input inventory investment. Intuitively, an opti-

\footnotetext{
${ }^{3}$ Notable exceptions that use inventories by stage of production as in this study are Banerjee and Mizen (2006) who stress the importance of the order of integration in the inventory-sales ratio, Sensier (2003) who analyses an error correction equilibrium model and Guariglia (1999) who uses annual company data and examine the effects of financial constraints on the accumulation of inventories.
} 
mizing firm that decides to draw down finished goods inventories will typically increase production in the future to correct this imbalance. To the extent that deliveries and usage of (materials and intermediate goods) are not perfectly synchronized this correction will affect input inventories as well because the firm has to draw down input inventories in order to increase production.

The rest of this section formally describes the input-output inventory model. This model address several shortcomings of the traditional output inventory model and nests the latter as a special case. We follow closely the exposition of Humphreys et al. (2001) and highlight the extensions we make to the model where appropriate. ${ }^{4}$

We assume a representative firm that minimizes the present discounted value of expected total costs by choosing input $\left(M_{t}\right)$, output $\left(N_{t}\right)$ inventories and materials usage $\left(U_{t}\right)$. Input inventories $\left(M_{t}\right.$, i.e. materials and intermediate products) arrive in the firm by delivery from an outside supplier. The supplier charges a price $\left(V_{t}\right)$ per unit and the firm can adjust this stock by varying the usage in production and the flow of deliveries. The firm also hires labour from a competitive market at a real wage equal to $W_{t}$. Finally, the firm sells $\left(X_{t}\right)$ its finished product to downstream firms and consumers. The delivery price, $V_{t}$ as well as real wage rate, $W_{t}$ are viewed as exogenous. Similarly and following the tradition of the bulk of the literature demand $\left(X_{t}\right)$ for the firm's final product is also treated as exogenous. Total costs consist of labour costs, inventory holding costs, and delivery costs and are approximated with suitable quadratic forms. ${ }^{5}$ Formally, the firm's problem is defined as:

$$
\min _{U_{t}, M_{t}, N_{t}} E_{0} \sum_{t=0}^{\infty}\left[\prod_{j=0}^{t-1} \beta_{j}\right]\left(T C_{t}\right)
$$

s.t.

$$
\begin{gathered}
T C_{t}=\left(\frac{\gamma_{1}}{2}\right) Y_{t}^{2}+\left(\frac{\gamma_{2}}{2}\right) U_{t}^{2}+\gamma_{3} Y_{t} U_{t}+\left(\frac{\varphi}{2}\right)\left[\gamma_{6} \Delta Y_{t}+\gamma_{7} \Delta U_{t}\right]^{2}+W_{t}\left[\gamma_{4} Y_{t}+\gamma_{5} U_{t}\right]+\varepsilon_{y t}\left(\gamma_{8} Y_{t}+\gamma_{9} U_{t}\right) \\
+\left(\delta_{0}+\varepsilon_{n t}\right) N_{t}+\left(\frac{\delta}{2}\right)\left(N_{t}-\alpha X_{t}\right)^{2}+\left(\tau_{0}+\varepsilon_{m t}\right) M_{t}+\left(\frac{\tau}{2}\right)\left(M_{t}-\theta Y_{t}\right)^{2} \\
+V_{t} D_{t}+\left(\frac{\phi}{2}\right) D_{t}^{2}
\end{gathered}
$$

\footnotetext{
${ }^{4}$ To conserve space we intentionally keep the description of the model short. We refer the reader to Humphreys et al. (2001) for all the underlying details.

${ }^{5}$ There are two simplifying assumptions that are maintained in this model: (a) capital is assumed to be fixed in the frequency we examine and (b) the firm acquires materials as well as intermediate goods (work-in-process) from outside suppliers. The first assumption allows to suppress capital in the production function and consequently in the cost function below while the second to lump together raw materials and work-in-process inventories. Assumption (a) is typically maintained in the empirical inventory literature that works with the linear quadratic model.
} 


$$
\begin{gathered}
N_{t}-N_{t-1}=Y_{t}-X_{t} \\
M_{t}-M_{t-1}=D_{t}-U_{t}
\end{gathered}
$$

Equation (2.2) defines a quadratic approximation to the total cost function and equations (2.3)(2.4) define the inventory accumulation laws of motion. $Y_{t}$ denotes production, $X_{t}$ is sales, $D_{t}$ is deliveries, $\varepsilon_{y t}$ is a technology shock. $\varepsilon_{m t}, \varepsilon_{n t}$ denote holding cost shocks for input and output inventories respectively. We will specify the distributional assumptions on the stochastic elements of the environment in section 3. Notice that the discount factor $\beta_{j}=\frac{1}{1+R_{j}}$ in (2.1) is allowed to vary with the real interest rate, $R_{j}$ over time. The first line of the total cost function describes the approximation to the labour cost function. Since input inventories are explicitly considered this function includes materials usage as an additional argument. This formulation nests the cost function (by setting $U_{t}=0$ ) used in the standard output linear-quadratic inventory model. The first four terms in the labour cost function capture marginal costs and marginal adjustment costs that vary with the level of production $\left(Y_{t}\right)$ and usage $\left(U_{t}\right)$ and the change in production $\left(\Delta Y_{t}\right)$ and usage $\left(\Delta U_{t}\right)$ respectively. The last two terms that involve the wage rate $\left(W_{t}\right)$ and the technology shock allow for cost shocks arising from variation in wages and technology. The second line of total costs describes inventory holding (e.g. storage and insurance), backlog and stock-out costs separately specified for each type of stock. $\alpha X_{t}$ and $\theta Y_{t}$ are assumed to equal the target or "desired" stocks for output and input inventories respectively. The final line of equation (2.2) specifies the cost associated with deliveries of materials. Materials are acquired at price $\left(V_{t}\right)$ per unit and the delivery costs also embody (adjustment) costs for the rapid delivery of materials (and/or intermediate products). ${ }^{6}$ The parameters that appear in equation (2.2) (i.e. $\gamma_{1}$ through $\gamma_{9}$ ) satisfy a number of theoretical restrictions that follow from the concavity of the underlying short-run production function.

For reasons of parsimony we follow Humphreys et al. (2001) and focus on two specifications for the labour cost function (first line of (2.2)) that imply further restrictions on $\gamma_{1}$ through $\gamma_{9}$. These depend on the separability of usage in the production function. ${ }^{7}$

Value added. Under the assumption of separability of materials usage in production we define the value added specification. The parametric restrictions we employ are given below.

\footnotetext{
${ }^{6}$ Note that $V_{t} D_{t}$ is the only term that appears without a parameter and allows identification of the remaining (except the target stock parameters which are separately identified) structural parameters relative to units in which $V_{t}$ is measured.

${ }^{7}$ After suppressing capital input the production function is given by $Y_{t}=F\left(L_{t}, U_{t}, \varepsilon_{y t}\right)$. Assuming that $U_{t}$ is additively separable from other factors of production yields $Y_{t}=f\left(L_{t}, \varepsilon_{y t}\right)+U_{t}$.
} 


$$
\begin{gathered}
\gamma_{1}=\gamma_{2}=-\gamma_{3}=\gamma>0, \quad \gamma_{4}=-\gamma_{5}>0 \\
\gamma_{6}=-\gamma_{7}=-\gamma_{8}=\gamma_{9}=1
\end{gathered}
$$

The labour cost function (first line of (2.2)) is then given by:

$$
\left(\frac{\gamma}{2}\right)\left(Y_{t}-U_{t}\right)^{2}+\gamma_{4} W_{t}\left(Y_{t}-U_{t}\right)+\left(\frac{\varphi}{2}\right)\left(\Delta Y_{t}-\Delta U_{t}\right)^{2}-\varepsilon_{y t}\left(Y_{t}-U_{t}\right)
$$

Gross production. An alternative specification arises when materials usage is not separable from labour. This specification employs the following parametric restrictions.

$$
\gamma_{5}=\gamma_{7}=\gamma_{9}=0, \quad \gamma_{6}=-\gamma_{8}=1
$$

The labour cost function (first line of (2.2)) is then given by:

$$
\left(\frac{\gamma_{1}}{2}\right) Y_{t}^{2}+\left(\frac{\gamma_{2}}{2}\right) U_{t}^{2}+\gamma_{3} Y_{t} U_{t}+\gamma_{4} W_{t} Y_{t}+\left(\frac{\varphi}{2}\right)\left(\Delta Y_{t}\right)^{2}-\varepsilon_{y t} Y_{t}
$$

\subsection{Euler equations}

The firm's problem defined by (2.1)-(2.4) yields Euler equations for $U_{t}, M_{t}$, and $N_{t}$. However, we are going to utilize only the Euler equations for input $\left(M_{t}\right)$ and output $\left(N_{t}\right)$ inventories (usage will be eliminated by solving its Euler equation in terms of the rest of the variables) since usage $\left(U_{t}\right)$ and deliveries $\left(D_{t}\right)$ are unobservable in our dataset.

Let $L$ be the lag operator which works as the lead operator when inverted (i.e. $L \Upsilon_{t}=\Upsilon_{t-1}$ and $\left.L^{-1} \Upsilon_{t}=\Upsilon_{t+1}\right)$. The Euler equations for the value added specification are as follows. ${ }^{8}$

Input inventories

$$
\begin{gathered}
E_{t}\left\{\gamma \phi\left(\left(M_{t}-M_{t-1}\right)-\beta_{t+1}\left(M_{t+1}-M_{t}\right)\right)+\phi \varphi\left(1-\beta_{t+1} L^{-1}\right)\left(\left(\Delta M_{t}-\Delta M_{t-1}\right)-\beta_{t+1}\left(\Delta M_{t+1}-\Delta M_{t}\right)\right)\right. \\
+\gamma\left(V_{t}-\beta_{t+1} V_{t+1}\right)+\phi \gamma_{4}\left(W_{t}-\beta_{t+1} W_{t+1}\right)+\varphi\left(1-\beta_{t+1} L^{-1}\right)\left(\Delta V_{t}-\beta_{t+1} \Delta V_{t+1}\right) \\
+\gamma \phi\left(Y_{t}-\beta_{t+1} Y_{t+1}\right)+\phi \varphi\left(1-\beta_{t+1} L^{-1}\right)\left(\Delta Y_{t}-\beta_{t+1} \Delta Y_{t+1}\right)+\tau(\gamma+\phi)\left[M_{t}-\theta Y_{t}\right] \\
+\tau \varphi\left[\left(\Delta M_{t}-\theta \Delta Y_{t}\right)-\beta_{t+1}\left(\Delta M_{t+1}-\theta \Delta Y_{t+1}\right)\right] \\
\left.+\tau_{0}-\phi\left(\varepsilon_{y, t}-\beta_{t+1} \varepsilon_{y, t+1}\right)+(\gamma+\phi) \varepsilon_{m t}+\varphi\left(\varepsilon_{m t}-\beta_{t+1} \varepsilon_{m, t+1}\right)\right\}=0
\end{gathered}
$$

Output inventories

${ }^{8}$ The derivation details are given in the online Appendix. 


$$
\begin{gathered}
E_{t}\left\{\delta(\gamma+\phi)\left[N_{t}-\alpha X_{t}\right]+\delta \varphi\left[\Delta N_{t}-\alpha \Delta X_{t}\right]\right. \\
-\tau(\gamma+\phi)\left[(1+\theta)\left(M_{t}-\theta Y_{t}\right)-\theta \beta_{t+1}\left(M_{t+1}-\theta Y_{t+1}\right)\right] \\
-\tau \varphi\left[(1+\theta)\left(\Delta M_{t}-\theta \Delta Y_{t}\right)-\theta \beta_{t+1}\left(\Delta M_{t+1}-\theta \Delta Y_{t+1}\right)\right] \\
\left.+\delta_{0}+(\gamma+\phi) \varepsilon_{n t}+\varphi\left(\varepsilon_{n t}-\beta_{t+1} \varepsilon_{n, t+1}\right)-(\gamma+\phi) \varepsilon_{m t}-\varphi\left(\varepsilon_{m t}-\beta_{t+1} \varepsilon_{m, t+1}\right)\right\}=0
\end{gathered}
$$

Notice that the time-varying discount factor, $\beta_{t+1}$ appears in both Euler equations. This implies that the Euler equations become non-linear in the real interest rate. However our solution method cannot handle expectational difference equations that are non-linear in variables. To circumvent this difficulty we linearise the Euler equations around the long run (i.e. sample mean) values of the variables (see the online Appendix for the details). This procedure gives rise to the following Euler equations:

Input inventories

$$
\begin{gathered}
E_{t}\left\{\gamma \phi\left(\left(M_{t}-M_{t-1}\right)-\bar{\beta}\left(M_{t+1}-M_{t}\right)\right)+\phi \varphi\left(1-\bar{\beta} L^{-1}\right)\left(\left(\Delta M_{t}-\Delta M_{t-1}\right)-\bar{\beta}\left(\Delta M_{t+1}-\Delta M_{t}\right)\right)\right. \\
+\gamma\left(V_{t}-\bar{\beta} V_{t+1}\right)+\phi \gamma_{4}\left(W_{t}-\bar{\beta} W_{t+1}\right)+\varphi\left(1-\bar{\beta} L^{-1}\right)\left(\Delta V_{t}-\bar{\beta} \Delta V_{t+1}\right) \\
+\gamma \phi\left(Y_{t}-\bar{\beta} Y_{t+1}\right)+\phi \varphi\left(1-\bar{\beta} L^{-1}\right)\left(\Delta Y_{t}-\bar{\beta} \Delta Y_{t+1}\right)+\tau(\gamma+\phi)\left[M_{t}-\theta Y_{t}\right] \\
+\tau \varphi\left[\left(\Delta M_{t}-\theta \Delta Y_{t}\right)-\bar{\beta}\left(\Delta M_{t+1}-\theta \Delta Y_{t+1}\right)\right] \\
\left.-\phi\left(\varepsilon_{y, t}-\bar{\beta} \varepsilon_{y, t+1}\right)+(\gamma+\phi) \varepsilon_{m t}+\varphi\left(\varepsilon_{m t}-\bar{\beta} \varepsilon_{m, t+1}\right)+\overline{\beta^{2}}\left(\gamma \bar{V}+\phi \gamma_{4} \bar{W}+\phi \gamma \bar{X}\right) r_{t+1}+c_{0}\right\}=0
\end{gathered}
$$

Output inventories

$$
\begin{gathered}
E_{t}\left\{\delta(\gamma+\phi)\left[N_{t}-\alpha X_{t}\right]+\delta \varphi\left[\Delta N_{t}-\alpha \Delta X_{t}\right]\right. \\
-\tau(\gamma+\phi)\left[(1+\theta)\left(M_{t}-\theta Y_{t}\right)-\theta \bar{\beta}\left(M_{t+1}-\theta Y_{t+1}\right)\right] \\
-\tau \varphi\left[(1+\theta)\left(\Delta M_{t}-\theta \Delta Y_{t}\right)-\theta \bar{\beta}\left(\Delta M_{t+1}-\theta \Delta Y_{t+1}\right)\right] \\
+\delta_{0}+(\gamma+\phi) \varepsilon_{n t}+\varphi\left(\varepsilon_{n t}-\bar{\beta} \varepsilon_{n, t+1}\right)-(\gamma+\phi) \varepsilon_{m t}-\varphi\left(\varepsilon_{m t}-\bar{\beta} \varepsilon_{m, t+1}\right) \\
\left.-\tau(\gamma+\phi) \theta\left((\tau(\gamma+\phi))^{-1}\left(-\gamma(1-\bar{\beta}) \bar{V}-\phi \gamma_{4}(1-\bar{\beta}) \bar{W}-\phi \gamma(1-\bar{\beta}) \bar{X}-\tau_{0}\right)\right) \overline{\beta^{2}} r_{t+1}+d_{0}\right\}=0
\end{gathered}
$$

where a bar above a variable denotes the sample mean of the respective variable and $c_{0}=$ $\tau_{0}-\overline{\beta^{2}} \bar{r}\left(\gamma \bar{V}+\phi \gamma_{4} \bar{W}+\phi \gamma \bar{X}\right), d_{0}=\delta_{0}+\tau(\gamma+\phi) \theta\left((\tau(\gamma+\phi))^{-1}\left(-\gamma(1-\bar{\beta}) \bar{V}-\phi \gamma_{4}(1-\bar{\beta}) \bar{W}-\right.\right.$ $\left.\left.\phi \gamma(1-\bar{\beta}) \bar{X}-\tau_{0}\right)\right) \overline{\beta^{2}} \bar{r}$.

As the Euler equations above illustrate the coefficients that appear on the (expected) real interest rate are a function of $\gamma, \gamma_{4}, \phi, \theta$, i.e. parameters that govern production costs, materials 
delivery adjustment costs and inventory holding costs respectively. Thus whether input and output inventories will exhibit any sensitivity to short-run real interest rate variation crucially depends on these parameters. The Euler equations for the gross production specification are described in the online Appendix.

The Euler equations describe the trade-offs facing the firm in deciding for the optimal input and output inventories. These dynamic trade-offs are similar in the value added and gross production specifications. Below we offer a brief description that helps to highlight the interaction between the different types of stocks. This interaction is a key feature of the data and will figure prominently in the empirical results in section 3 .

The input $\left(M_{t}\right)$ inventory Euler equation states that the firm balances the marginal cost of ordering and holding input inventories today against the cost of ordering input inventories next period. Similarly the output $\left(N_{t}\right)$ inventory Euler equation states that the firm balances the marginal cost of producing a good and storing it as inventory this period against the cost of producing the good in the future. Most notably these Euler equations make evident the interaction between the two type of stocks. For example, the output $\left(N_{t}\right)$ Euler equation (value added specification, equation (2.8)) explicitly incorporates input inventories $\left(M_{t}\right)$. The role of input inventories in this equation arises through the gap terms, $M_{t+i}-\theta Y_{t+i}, \Delta M_{t+i}-\theta \Delta Y_{t+i}, i=0,1$. The firm attempts to eliminate deviations from the target level of stocks, $\theta Y_{t}, \alpha X_{t}$. Optimality dictates balancing input and output inventory gaps. The parameters $\gamma, \delta, \tau, \varphi, \theta, \phi$ indicate the relative frictions that these actions entail. For instance, all else equal, an increase in the (absolute) input inventory gap $\left(M_{t}-\theta Y_{t}\right)$ entails a stock-out cost. With stock-out costs that are quadratic (see second line of equation (2.2)) it is cost minimizing to spread the stock-out costs between inventory stocks rather than tolerate a negative gap and a zero gap. Hence the firm will find it optimal to adjust output inventories $N_{t}$ in order to balance these costs. The extent of the adjustment will depend on the relative magnitude of the stock-out cost $(\delta)$ compared to the marginal production and marginal adjustment cost parameters $(\gamma, \varphi)$ since the firm will need to adjust production in order to adjust inventories.

The addition of a variable discount factor in the Euler equations enables us to study and estimate the link between the real interest rate and inventories. For instance, the expected real interest rate term in the input Euler equation (2.9) captures the marginal interest rate cost from ordering an extra unit of materials today and storing it as inventory. Variation in the real interest rate imply that firms will attempt to shift the delivery of materials from periods when it is relatively costly to order and store materials (when interest rates are high) to periods when it is relatively inexpensive. Moreover, an important consequence of stock interaction is the link between the 
inventory decisions. Because of this stock interaction (for the cost-minimising reasons explained above) a firm that decides for example to cut deliveries and keep a lower input inventory in response to higher interest rates will inevitably find it optimal to reduce output inventories as well. We will analyse and explore this mode of interaction later in section 3 where we discuss the dynamic properties of the model.

\section{Estimation methodology and results}

This section describes the estimation procedure we adopt for the input-output inventory model. The model consists of nine equations. The two Euler equations for input and output inventories, and seven equations that describe the exogenous variables of the model. The exogenous variables can be separated in two blocks. One block consists of the exogenous observable processes, i.e. sales $\left(X_{t}\right)$, real wage $\left(W_{t}\right)$, real materials price $\left(V_{t}\right)$ and the real interest rate $\left(R_{t}\right)$. The second block consists of the unobserved exogenous processes (technology and inventory holding cost shocks), $\varepsilon_{y t}, \varepsilon_{m t}, \varepsilon_{n t}$. We assume that all of the exogenous variables are governed by $\mathrm{AR}(1)$ processes and collect them in the vector $Z_{t}$,

$$
Z_{t}=A Z_{t-1}+\omega_{t}
$$

where,

$$
\begin{gathered}
Z_{t}=\left[X_{t} W_{t} V_{t} R_{t} \varepsilon_{m t} \varepsilon_{n t} \varepsilon_{y t}\right]^{\prime} \\
A=\left[\begin{array}{ccccccc}
\rho_{x} & 0 & 0 & 0 & 0 & 0 & 0 \\
0 & \rho_{w} & 0 & 0 & 0 & 0 & 0 \\
0 & 0 & \rho_{v} & 0 & 0 & 0 & 0 \\
0 & 0 & 0 & \rho_{r} & 0 & 0 & 0 \\
0 & 0 & 0 & 0 & \rho_{m} & 0 & 0 \\
0 & 0 & 0 & 0 & 0 & \rho_{n} & 0 \\
0 & 0 & 0 & 0 & 0 & 0 & \rho_{y}
\end{array}\right]
\end{gathered}
$$

and the fundamental shocks $\omega_{t}=\left[\varepsilon_{x t}, \varepsilon_{w t}, \varepsilon_{v t}, \varepsilon_{r t}, \nu_{m t}, \nu_{n t}, \nu_{y t}\right]^{\prime}$ are distributed i.i.d with a diagonal variance-covariance matrix,

$$
\Sigma=\operatorname{diag}\left(\sigma_{x}^{2}, \sigma_{w}^{2}, \sigma_{v}^{2}, \sigma_{r}^{2}, \sigma_{\nu_{m}}^{2}, \sigma_{\nu_{n}}^{2}, \sigma_{\nu_{y}}^{2}\right)
$$

The Euler equations for input and output inventories along with equation (3.1) define a system of linear expectational difference equations that can be solved to yield the decision rules for the model. Using standard numerical methods (as in Klein (2000)) the solution to this system can be written compactly as, 


$$
s_{t}=\Gamma(\Theta) s_{t-1}+\Omega(\Theta) \omega_{t}
$$

where $s_{t}=\left[M_{t} N_{t} Z_{t} M_{t-1} N_{t-1}\right]^{\prime}$ and $\Theta$ denotes the parameter vector to be estimated. $\Theta$ contains 22(24) parameters in the value added (gross production) version of the model respectively. $\Gamma(\Theta)$ is an eleven by eleven, and $\Omega(\Theta)$ an eleven by seven matrix of reduced form parameters that depend non-linearly on the structural parameter vector $\Theta$.

We adopt a Bayesian (maximum likelihood) approach in order to estimate the structural parameters of the model. Maximum likelihood estimation of the decision rules is shown to resolve many problems with generalised method of moments (GMM) estimators applied on Euler equations in linear-quadratic inventory models. As Fuhrer et al. (1995) demonstrate using a linear-quadratic inventory model, maximum likelihood dominates generalised method of moments estimators along every dimension (see page 150). The Bayesian approach has gained ground recently, especially in applied work with dynamic stochastic general equilibrium (DSGE) models. ${ }^{9}$

The Bayesian approach we adopt combines prior (non-sample) information along with information contained in the data. The non-sample information is summarized with a prior distribution with density $p(\Theta) .{ }^{10}$ The sample information (conditional on model $\mathcal{M}_{i}$ ) is contained in the likelihood function, $\mathcal{L}\left(\Theta \mid \mathbf{Y}_{T}, \mathcal{M}_{i}\right)$, where $\mathbf{Y}_{T}=\left[Y_{1}, \ldots, Y_{T}\right]$ contains the data. The likelihood function allows us to update the prior distribution of $\Theta$. Let $p\left(\mathbf{Y}_{T} \mid \Theta, \mathcal{M}_{i}\right)=\mathcal{L}\left(\Theta \mid \mathbf{Y}_{T}, \mathcal{M}_{i}\right)$ denote the likelihood function of version $\mathcal{M}_{i}$ of the input-output inventory model. Then using Bayes' theorem we can express the posterior distribution of the parameters as:

$$
p\left(\Theta \mid \mathbf{Y}_{T}, \mathcal{M}_{i}\right)=\frac{p\left(\mathbf{Y}_{T} \mid \Theta, \mathcal{M}_{i}\right) p(\Theta)}{p\left(\mathbf{Y}_{T} \mid \mathcal{M}_{i}\right)}
$$

where the denominator, $p\left(\mathbf{Y}_{T} \mid \mathcal{M}_{i}\right)=\int p\left(\Theta, \mathbf{Y}_{T} \mid \mathcal{M}_{i}\right) d \Theta$, in the equation above is the marginal data density conditional on model $\mathcal{M}_{i}$. In Bayesian analysis the marginal data density constitutes a measure of model fit with two dimensions: goodness of in-sample fit and a penalty for model complexity. We will use this measure below to evaluate the ability of the two competing specifications to fit the data. ${ }^{11}$

\footnotetext{
${ }^{9}$ See for example Schorfheide (2000) and Smets and Wouters (2003) for representative studies. A recent application that explicitly incorporates input and output inventories in general equilibrium, as in this paper, is a study by Iacoviello et al. (2007).

${ }^{10}$ We assume that parameters are a priori independent from each other which implies the joint prior distribution equals the product of marginal priors.

${ }^{11}$ The posterior distribution of parameters is evaluated numerically using the Metropolis-Hastings algorithm. We utilise five parallel chains, initiate each chain from the posterior mode and discard the first half of parameter draws from each chain. We also calculate convergence diagnostics in order to check and ensure the stability of the posterior distributions of parameters as described in Brooks and Gelman (1998).
} 
We estimate the two model specifications as described in section 2. Model $V A\left(\mathcal{M}_{V A}\right)$ incorporates the value added restriction while model $G P\left(\mathcal{M}_{G P}\right)$ the gross production restriction. The first four columns in Table 3 list the parameters and the assumptions on the prior distributions. We use fairly loose priors for all parameters. To specify priors we draw information from Humphreys et al. (2001) and Tsoukalas (2005). Both studies estimate a subset of these parameters with a constant interest rate version of the input-output inventory model. The general rule we follow for all the cost function parameters $(\gamma$ through $\delta$ ) is to specify prior means consistent with the estimated values reported in Tsoukalas (2005) with standard errors such that the parameter domain covers the estimated values of the corresponding parameters reported in Humphreys et al. (2001). The only difference in the prior distributions across specifications concerns the delivery adjustment cost parameter $(\phi)$ - where for the gross production model we use a prior mean and standard deviation as implied by the values reported in Humphreys et al. (2001) - and the persistence parameter for the output inventory holding cost shock, $\rho_{n} \cdot{ }^{12}$ The parameters that characterize the persistence of the exogenous observable variables of the model $\left(X_{t}, V_{t}, W_{t}\right)$ are assumed to follow a beta distribution with a mean of 0.9 and standard error of 0.05 . Again we use the estimated values from Tsoukalas (2005) to guide us on the choice of priors for these parameters. We have estimated an $\mathrm{AR}(1)$ process for the real interest rate $\left(R_{t}\right)$ using pre-sample data (1956Q1-1962Q4) in order to set the prior for the real interest rate process (i.e. $\rho_{r}$ and $\sigma_{r}^{2}$ ). The parameters that characterize the persistence of the exogenous un-observable variables of the model $\left(\varepsilon_{m t}, \varepsilon_{n t}, \varepsilon_{y t}\right)$ are assumed to follow a uniform distribution between zero and one since we lack any non-sample information to draw from. Finally the standard errors of the shocks to the $\operatorname{AR}(1)$ processes (with the exception of $\varepsilon_{y t}$ which we do not have any information) are assumed to follow an inverse gamma distribution with a mean corresponding to the value estimated in Tsoukalas (2005) and two degrees of freedom. This distribution guarantees a rather large domain and a positive and un-restricted variance.

To estimate the model we use quarterly data from 1963Q1 to 2004Q4. Since the solution of the model implies that variables fluctuate around stationary values we de-trend and/or de-mean the data with linear or quadratic trends (in the case of the real materials price). ${ }^{13}$ Our baseline measure for the real interest rate is defined as the 3-month Treasury-bill rate less the inflation rate calculated from the GDP deflator. All data except the real interest rates are in logs. Details about

\footnotetext{
${ }^{12}$ The posterior mode for the delivery cost parameter turned out to be orders of magnitudes higher compared to the prior domain for the gross production specification. This created maximisation and convergence problems for several parameters. We have thus chosen to modify this prior such that is centered around the average value in Humphreys et al. (2001)(i.e. averaging across all reported estimated values). Similarly, when we estimated the gross production specification with a uniform prior on $\rho_{n}$ as in the value added case produced a zero value for this parameter. We have thus specified a white noise process for $\varepsilon_{n}$.

${ }^{13}$ We formally test stationarity of the de-trended data using the ADF and the KPSS tests. The tests reject (cannot reject in the latter) the null of unit root (the null of stationarity) at conventional significance levels.
} 
the data sources are given in the data Appendix. ${ }^{14}$

Table 3 reports the posterior mean and 10 and 90 percent quartiles for the parameters of the input-output inventory model. In general the data are quite informative about the structural parameters of the cost function. ${ }^{15}$ Most parameters are estimated significantly different from zero, and the posterior distributions show that most parameters exhibit a shift in the location and or more concentration around the mean compared to the prior distributions suggesting that the data are quite informative for the parameters. This is also true for the standard errors for the shocks. ${ }^{16}$ In general there are differences in the estimated parameters across specifications and the value added specification produces much more (economically) sensible results. For example the delivery cost parameter $\phi$ in the gross production specification is estimated implausibly large compared to the value added specification reflecting the failure to include costly changes in materials usage in the labour adjustment cost function. The target stock parameter $\alpha$ is also very large and implies firms hold 6 months worth of sales in inventory. The two stock-out parameters $(\delta, \tau)$ in the gross production specification imply implausibly large stock-out costs for output compared to input inventories (around 100 times larger). While these informal comparisons are helpful we nevertheless formally test the ability of each specification to fit the data by using the posterior odds ratio which is calculated as:

$$
\frac{\pi_{\mathcal{M}_{\mathcal{V}}}}{\pi_{\mathcal{M}_{\mathcal{G P}}}} \cdot \frac{p\left(Y_{T} \mid \mathcal{M}_{\mathcal{V A}}\right)}{p\left(Y_{T} \mid \mathcal{M}_{\mathcal{G P}}\right)}
$$

where the first term is the prior odds ratio and the second term the Bayes factor formed by the ratio of the marginal data densities (denominator of (3.3)). The log marginal data densities for models $\mathcal{M}_{\mathcal{V} \mathcal{A}}, \mathcal{M}_{\mathcal{G P}}$ are equal to $2444.9,2399.9$ respectively. Assuming a prior odds ratio of one (giving equal chance to each version) this calculation yields a posterior odds ratio equal to $3.5 e^{1} 9$ $(\exp (45))$, which favours overwhelmingly the value added specification. ${ }^{17}$ In what follows therefore we focus on results from the value added specification.

The (posterior mean) target stock parameters $\theta(\alpha)$ imply that firms aim to hold around 75

\footnotetext{
${ }^{14}$ In addition to the Treasury-bill definition we have also considered a weighted average cost of capital (WACC) measure, intended to capture a "real cost of finance" and the Bank of England repo rate. The former combines the cost of debt and equity facing companies. Estimation results using this (or the Bank of England repo rate) measure of the real interest rate are broadly similar and are not reported for brevity but are available upon request.

${ }^{15}$ Figures 1,2 and 3 in the online Appendix present the prior and posterior distributions of the parameters of the input-output inventory model for the value added specification.

${ }^{16}$ The consequence of ignoring the joint interaction of the two types of stocks in terms of significance and plausibility of estimated parameters is addressed in the working paper version (see Tsoukalas (2005)). There we estimate single equations (i.e. separately for input and output inventories) and contrast the results with the joint input-output inventory model. In general joint estimation yields economically plausible and more precisely estimated structural parameters compared to single equation estimation.

${ }^{17}$ To calculate the marginal data density given model $M_{i}, i=1,2, p\left(Y_{T} \mid M_{i}\right)$ we use the modified harmonic mean estimator proposed in Geweke (1999).
} 
(120) percent of a quarter worth of production (sales) in input (output) inventories respectively. Marginal adjustment costs of production as captured by $\varphi$ are significantly greater than either holding cost parameter $(\tau, \delta)$. The same is true for the marginal delivery cost parameter $\phi$. Both of these estimates imply that the firm places more weight on the costs associated with changing the normal flow of production or deliveries compared to the costs arising from holding and/or stocking out of inventories. These differences in parameters are needed to explain the persistence in both types of inventories. Moreover, the estimates suggest that marginal production costs are largely driven by variations in marginal adjustment costs rather than marginal costs $\left(\gamma, \gamma_{4}\right)$ arising with production or real wage variation respectively. ${ }^{18}$ Last, it is straightforward to show (using the second derivative with respect to $Y_{t}$ in equation (2.2)) that the slope of the marginal total cost (accounting for adjustment costs) function is:

$$
\frac{\partial^{2} T C}{\partial Y^{2}}=\gamma+(1+\bar{\beta}) \varphi
$$

Evaluated at the posterior means for $\gamma$ and $\varphi$ this slope equals 8.18. A positive slope implies a convex total cost function. The convexity of the cost function - as well as the relatively modest revenue motive that the parameters $\tau, \delta, \theta, \alpha$ imply —is key for the production smoothing behaviour of inventories. We analyze the implications of the convexity in the next section.

\subsection{Impulse response functions}

This section presents impulse response functions of input and output inventories to three fundamental shocks. We focus on the response of input and output inventories to a real interest rate, sales and technology shock (using the estimation results from the value added specification). All three Figures below depict median responses to a unit standard deviation shock along with the 10th and 90th percentiles.

Figure 1 shows that both type of stocks respond negatively to a rise in the real interest rate (corresponds to an increase of 1.7 percent). The effect is significant and the peak in the (median) responses imply that output inventories decline by 0.20 of a percent, while input inventories by 0.15 of a percent (relative to trend). Thus a rise in the real interest rate causes firms to reduce their inventory holding by a small amount. This is consistent with a direct monetary policy channel to the extent that changes in the policy rate transmit to changes in the real interest rate. Further, it is important to stress that this is a direct effect (holding all other influences constant) and thus can be interpreted as a lower bound on inventory adjustment following a change in the real interest rate. In fact there is evidence for the UK (see Benito (2005) and Guariglia (1999)) that changes

\footnotetext{
${ }^{18}$ This finding is similar to the evidence provided in Ramey and West (1999) for the US (see Table 11).
} 
in policy rates may bring about larger adjustments through changes in corporate balance sheets and bank lending. The rise in the real interest rate implies that ordering and storing materials today becomes more expensive compared to ordering materials in the future. Thus the firm rearranges materials deliveries intertemporaly to periods when the interest rate cost is lower. As a result current deliveries decline and so do input inventories. Since the shock is quite persistent $\left(\rho_{r}=0.914\right)$ and the marginal cost of changing the normal flow of delivery is high (i.e. parameter $\phi)$ the maximum effect is delayed (occurs four quarters out). Moreover, reducing input inventories implies a change in the input inventory gap $\left(M_{t}-\theta Y_{t}\right)$ and due to the convexity of the holding cost component of the total cost the firm finds it optimal to balance this gap by adjusting output inventories as well. Hence the firm cuts production and output inventories as well and stock interaction is driving this response. Again, due to the high marginal cost associated with changing the normal production flow (i.e. parameter $\varphi$ ) the response is also hump shaped, with the peak response occurring a year after the shock.

Figure 2 presents the responses to a positive sales shock. With higher expected sales the target stock for output inventories $\left(\alpha X_{t}\right)$ rise persistently (the persistence parameter for sales is quite high at 0.762 ). Hence the firm would attempt to bring the actual stock as close as possible to the new target by raising production. The key friction that prevents instantaneous adjustment is the production adjustment cost (captured by $\varphi$ ). Note that the target for input inventories $\left(\theta Y_{t}\right)$ rises as well with the higher production rate. Initially however, both stocks decline. This implies that the firm does not increase production as much as sales, and instead satisfies some of the extra demand out of output inventories. This is the familiar production level smoothing result: inventories are used to smooth production relative to sales. This implies a negative output inventory gap (and an associated stock-out cost) and given the convexity of the holding cost function it becomes optimal for the firm to spread the stock-out costs across both types of stocks. This explains why the firm tolerates a negative input gap at the same time. The firm increases usage of materials out of the existing stock in order to increase production but due to the high adjustment costs on deliveries does not fully replenish the input stock. ${ }^{19}$ Moreover output inventories decline significantly more (confidence intervals do not overlap) than input inventories suggesting that they do the bulk of the production smoothing. Stocks rise slowly over time towards their pre-shock level because adjustment costs are very high relative to stock-out costs as we have discussed above. An implication of these parameter estimates is a low speed of adjustment for input and output

\footnotetext{
${ }^{19}$ This behaviour of input inventories is consistent with manufacturing industries that produce-to-order where work-in-process inventories are expected to be used for production smoothing reasons (see West (1999)). The parameter that largely determines the initial response of input inventories is $\phi$. For example simulations of the model with a lower value of $\phi$ preserves the production smoothing role of output inventories but input inventories rise immediately.
} 
inventories. This low adjustment speed is a pervasive characteristic of models with aggregate data (see for e.g. the discussion in sections 4 and 5 in Ramey and West (1999)). ${ }^{20}$

Finally, Figure 3 presents responses to a positive one standard deviation technology shock. Both inventory stocks rise following a positive technology shock suggesting a role for production cost smoothing. A positive technology shock implies that costs are temporarily lower today. Firms will take advantage of lower costs using both margins available. First by producing more output and storing it as output inventory. At the same time they increase deliveries and store the excess (over that required by production) as input inventory. The higher stocks can then be drawn down in periods when costs are high.

\subsection{The importance of shocks: variance decompositions}

We next turn to the question of the importance of the seven structural shocks that drive the inputoutput inventory model. Table 4 presents the forecast error variance decomposition of input and output inventories that are due to each shock at various horizons. A distinctive feature emerging from Table 4 is the dominance of technology shocks in explaining the forecast error variance. These shocks thus appear to be the dominant driving factor behind fluctuations of input and output inventories across all forecast horizons. For example, technology shocks at the cyclical frequencies (4 to 40 quarters) account for between 36 to 53 percent and over 60 percent in input and output inventory fluctuations respectively. If business cycles and in particular GDP fluctuations are driven by technological variations consistent with the evidence in Holland and Scott (1998) then inventory movements may be an important part of the propagation of these shocks, especially in recessions. Consistent with the impulse responses, sales shocks appear to be quite important for driving inventory movements especially for output inventories, but less so for input inventories. Sales shocks appear to be especially important at the one quarter frequency for finished goods inventories explaining nearly 30 percent of the forecast error variance. At the 4 to 40 horizons sales shocks account for around between 15 and 20 percent for output and between 5 to 12 percent for input inventories. Inventory holding cost shocks are also important. For output inventories the own holding cost shock accounts for approximately between 11 and 36 percent whereas the contribution of in the case of input inventories is somewhat larger (e.g. rises to around 44 percent). Finally materials price, wage and interest rate shocks play a very minimal role. For example, the

\footnotetext{
${ }^{20}$ Schuh (1996) has shown how adjustment speeds estimated with firm-level data are significantly larger than their counterparts estimated with aggregate data. This suggests that some sort of aggregation bias is present in studies with aggregate data. Aggregation bias arises because the "true" aggregate adjustment speed is time variant but a fixed parameter is imposed on the data. An interesting resolution comes from Coen-Pirani (2004) who argues that inventory targets vary with the price mark-up over the business cycle. The omission of the mark-up from the target stock may result in a downward bias of estimated adjustment speeds.
} 
largest contribution of interest rate shocks to the forecast error variance is $1.2 \%$ and $2.2 \%$ for input and output inventories respectively with materials price shocks accounting for slightly above this, whereas wage shocks contribution is nil.

\section{Conclusions}

We estimate a new model of input and output inventories using data for the UK manufacturing sector. Manufacturing stocks are more than a third of whole economy inventories and account for a considerable share in GDP declines in the UK economy. In order to address the neglect of input inventories we use the model originally developed in Humphreys et al. (2001) with several important methodological extensions. First by allowing for a time-varying interest rate we are able to estimate the effect of the latter on the optimal accumulation of input and output inventories. We document a negative relationship between either input or output inventories and the real interest rate in the short run. This is an important finding because it suggests that monetary policy can exert a moderate direct influence on the accumulation of inventories. Recent US research by Maccini et al. (2004) that attempts to estimate this relationship has instead identified a long-run relationship but do not find evidence of a short-run relationship. A likely hypothesis for rationalizing the different results across the two studies may lie in the fact that in the UK economy the short-term real interest rate is more than twice as volatile compared to the US economy. Thus, all else equal, firms in the UK are faced with significantly larger changes in the cost of holding inventories compared to the US and respond by building up or cutting down their inventories. ${ }^{21}$

The estimation results also reveal a strong production smoothing role for inventories. Output and to a lesser extent input inventories buffer production from sales surprises whereas both types of stocks buffer production from cost shocks. The underlying cause for this smoothing role is the convexity of the cost function. The variance decomposition exercise suggests that technology shocks are the dominant driving factor behind inventory movements, whereas sales and inventory holding cost shocks accounting for most of the remaining variation. A fruitful direction is to further decompose input inventories into materials and work-in-process in order to evaluate the precise role of each component, especially in light of the production smoothing role of the latter suggested by Figure 2. Another interesting direction is to explore the inventory behaviour of the wholesale and retail sectors. These sectors have gained in significance over the last decade relative to manufacturing. An interesting question is to examine how supplier-user relationships between

\footnotetext{
${ }^{21}$ The sample period examined for this calculation is $1963 \mathrm{Q} 1$ to $2004 \mathrm{Q} 4$. The difference in the volatility of the real interest rate across the two economies is almost fully explained by the higher volatility of inflation in the UK compared to the US. This explanation accords well with evidence of suboptimal UK monetary policy along many fronts especially prior to the 1990s provided in Nelson and Nikolov (2004).
} 
manufacturers' and wholesalers and/or retailers play a role in shaping inventory dynamics. Last, it will be interesting to apply the methodology of Maccini et al. (2004) to explore whether a longrun relationship between the real interest rate and inventories in the UK can also be identified to complement the evidence for the short-run relationship estimated in this paper. This may be more relevant in the period of the Great Moderation where the decline in the volatility of inflation will have considerably reduced abrupt swings in the cost of capital and may have therefore limited the incentives of firms to alter their inventory holdings. We hope that future research will make headway into these directions.

\section{References}

Banerjee, A. and Mizen, P.: 2006, A re-interpretation of the linear-quadratic model when inventories and sales are polynomially cointegrated, Journal of Applied Econometrics 21, 1249-1264.

Benito, A.: 2005, Financial pressure, monetary policy effects and inventories: Firm-level evidence from a market based and a bank-based financial system, Economica 72, 201-24.

Blinder, A. and Maccini, L.: 1991, Taking stock: A critical assessment of recent research on inventories, Journal of Economic Perspectives 5, 73-96.

Brooks, S. and Gelman, A.: 1998, General methods for monitoring convergence of iterative simulations, Journal of Computational and Graphical Statistics 7, 434-55.

Callen, T., Hall, S. and Henry, S.: 1990, Manufacturing stocks: Expectations, risk and cointegration, Economic Journal 100, 756-772.

Coen-Pirani, D.: 2004, Markups, aggregation, and inventory adjustment, American Economic Review 94(5), 1328-1353.

Cuthbertson, K. and Gasparro, D.: 1993, The determinants of manufacturing inventories in the UK, Economic Journal 103, 1479-92.

Fuhrer, J., Moore, G. and Schuh, S.: 1995, Estimating the linear quadratic inventory model: Maximum likelihood versus generalized method of moments, Journal of Monetary Economics $35,115-57$.

Geweke, J.: 1999, Using simulation methods for bayesian econometric models: Inference, development and communication, Econometric Reviews 18, 1-126. 
Guariglia, A.: 1999, The effects of financial constraints on inventory investment: Evidence from a panel of UK firms, Economica 66, 43-62.

Guariglia, A.: 2000, Inventory investment and capital market imperfections: A generalization of the linear quadratic inventory model, Oxford Bulletin of Economics and Statistics 62, 223-42.

Hall, S., Henry, S. and Wren-Lewis, S.: 1986, Manufacturing stocks and forward-looking expectations in the UK, Economica 53, 447-65.

Holland, A. and Scott, A.: 1998, The determinants of UK business cycles, Economic Journal 108, 1067-1092.

Holt, C., Modigliani, F., Muth, J. and Simon, H.: 1960, Planning production, inventories, and work force, Englewood Cliffs, NJ, Prentice-Hall.

Humphreys, B., Maccini, L. and Schuh, S.: 2001, Input and output inventories, Journal of Monetary Economics 47, 347-75.

Iacoviello, M., Schiantarelli, F. and Schuh, S.: 2007, Input and output inventories in general equilibrium, Department of Economics Working Paper 658, Boston College.

Jung, Y. and Yun, T.: 2005, Monetary policy shocks, inventory dynamics and price setting behavior, Working Paper 2006-02, Federal Reserve Bank of San Francisco.

Klein, P.: 2000, Using the generalized schur form to solve a multivariate linear rational expectations model, Journal of Economic Dynamics and Control 24, 1405-1423.

Maccini, L., Moore, G. and Schaller, H.: 2004, The interest rate learning and inventory investment, American Economic Review 94, 1303-27.

Maccini, L. and Pagan, A.: 2008, Inventories, fluctuations and business cycles, Manuscript, Johns Hopkins University.

Monetary Policy Committee: 1999, The transmission mechanism of monetary policy, Bank of England.

Nelson, E. and Nikolov, K.: 2004, Monetary policy and stagflation in the UK, Journal of Money, Credit, and Banking 36, 293-318.

Ramey, V.: 1989, Inventories as factors of production and economic fluctuations, American Economic Review 79, 338-54. 
Ramey, V. and West, K.: 1999, Inventories, in J. Taylor and M. Woodford (eds), Handbook of macroeconomics, Vol. 1B, Elsevier Science, North Holland, pp. 863-923.

Schorfheide, F.: 2000, Loss function evaluation of DSGE models, Journal of Applied Econometrics $15,645-70$.

Schuh, S.: 1996, Evidence on the link between firm-level and aggregate inventory behavior, Federal Reserve Board Working Paper 46.

Sensier, M.: 2003, Inventories and asymmetric business cycle fluctuations in the UK: A structural approach, Applied Economics 35, 387-402.

Smets, F. and Wouters, R.: 2003, An estimated dynamic stochastic general equilibrium model of the Euro Area, Journal of the European Economic Association 1, 1123-75.

Tsoukalas, J.: 2005, Modelling manufacturing inventories, Bank of England Working Paper 284.

West, K.: 1999, Order backlogs and production smoothing, The Economics of Inventory Management, A. Chikan and M. Lovell (eds.), Amsterdam: Elsevier Sience Publication pp. 305-318.

\section{Data Appendix}

The data used for this paper (except for the real cost of capital measure (WACC) which was supplied by the Bank of England) are published by the Office for National Statistics (ONS) and cover the period 1963Q1 to 2004Q4. Details are as follows. Consistent with the ONS definition (Index of Production publication), manufacturing sales data are constructed using the identity, $X=Y-\Delta N-\Delta W P$, where $Y$ is manufacturing production (gross production) and $\Delta N, \Delta W P$ is the change in finished goods, work-in-process inventories respectively. The input inventories series $M$ is obtained as the (chain weighted) sum of raw materials and supplies and work-in-process inventories. The output inventories series, $N$, is simply finished goods inventories. All inventory series refer to the total manufacturing sector, the only available level of aggregation. ${ }^{22}$ The raw materials price is the price index for materials and fuels purchased by all manufacturing industries. The nominal wage data are constructed as the product of unit wage cost and output per job to arrive at an index of wage per head. Because these series are not available prior to 1970 we use the corresponding whole economy series (1963-1969). ${ }^{23}$ The resulting index is converted to a nominal figure using the New Earnings Survey figure (2003 Q2) for average weekly earnings.

\footnotetext{
${ }^{22}$ The raw inventory data form the ONS refer to changes in stocks. The levels for stocks are derived by cumulating the corresponding series.

${ }^{23}$ We thank Richard Barwell for supplying this calculation.
} 
The nominal wage data and raw materials price data are deflated by the aggregate manufacturing producer price output index. The index reflects manufacturing output prices excluding duty. All manufacturing data are in logs, seasonally adjusted and in 2001 prices.

We use two measures of real interest rates. The ex-post real interest rate based on the three month Treasury-bill yield and the real weighted average cost of capital. The former is constructed as the difference between the three month Treasury bill rate and the inflation rate based on the GDP deflator. The weighted average cost of capital (WACC) is a textbook measure of the cost of finance for a representative firm. It is defined as a weighted average of the cost of debt and the cost of equity using the gearing ratio of debt to debt plus equity as the weighting factor. The real cost of debt finance is calculated as the risk-free interest rate measured using the ten year spot rate for the index linked yield curve plus a measure of spreads. The latter is for investment grade bonds, spliced together from the FTSE Debentures and Loans index and the Merrill Lynch index. The real cost of equity finance is calculated using a simple dividend discount model.

The ONS codes are as follows: Manufacturing output index-CKYY. Manufacturing output(finished goods) inventories - FBNH. Manufacturing work-in-process inventories-FBNG. Manufacturing materials and fuels inventories-FBNF. Manufacturing price index of materials and fuels - RNPE. Manufacturing output price index-PVNQ. Manufacturing output per job-LNNX. Manufacturing unit wage cost-LNNQ.

Table 1: Importance of inventory changes in UK recessions

\begin{tabular}{ccc}
\hline \hline Peak quarter-Trough quarter* & Total & Manufacturing \\
\hline 1973:2-1974:1 & 46 & 37 \\
$1975: 1-1975: 3$ & -29 & -120 \\
1979:4-1981:1 & 39 & 7 \\
1990:2-1991:3 & 67 & 13 \\
\hline Notes. Recessions are defined as periods accounting for at least two consecutive quarters of real GDP declin
\end{tabular}

Columns 2 and 3 are peak-trough change in inventory change as a percentage of the peak-trough fall in real GDP. 
Table 2: UK Manufacturing inventory facts

\begin{tabular}{ccc}
\hline & $\begin{array}{c}\text { Variance decomposition } \\
\text { of inventory investment }(\%)\end{array}$ & $\begin{array}{c}\text { Size } \\
(\%)\end{array}$ \\
\hline Total & 100 & 100 \\
Finished goods & 21 & 36 \\
Input & 53.5 & 64 \\
Covariance terms & 25.5 & n.a. \\
\hline Notes. UK data: Quarterly in 2001 prices over the period 1963Q1 to 2004Q4. \\
Size refers to average values over the sample.
\end{tabular}

Figure 1: One unit std.dev real interest rate shock
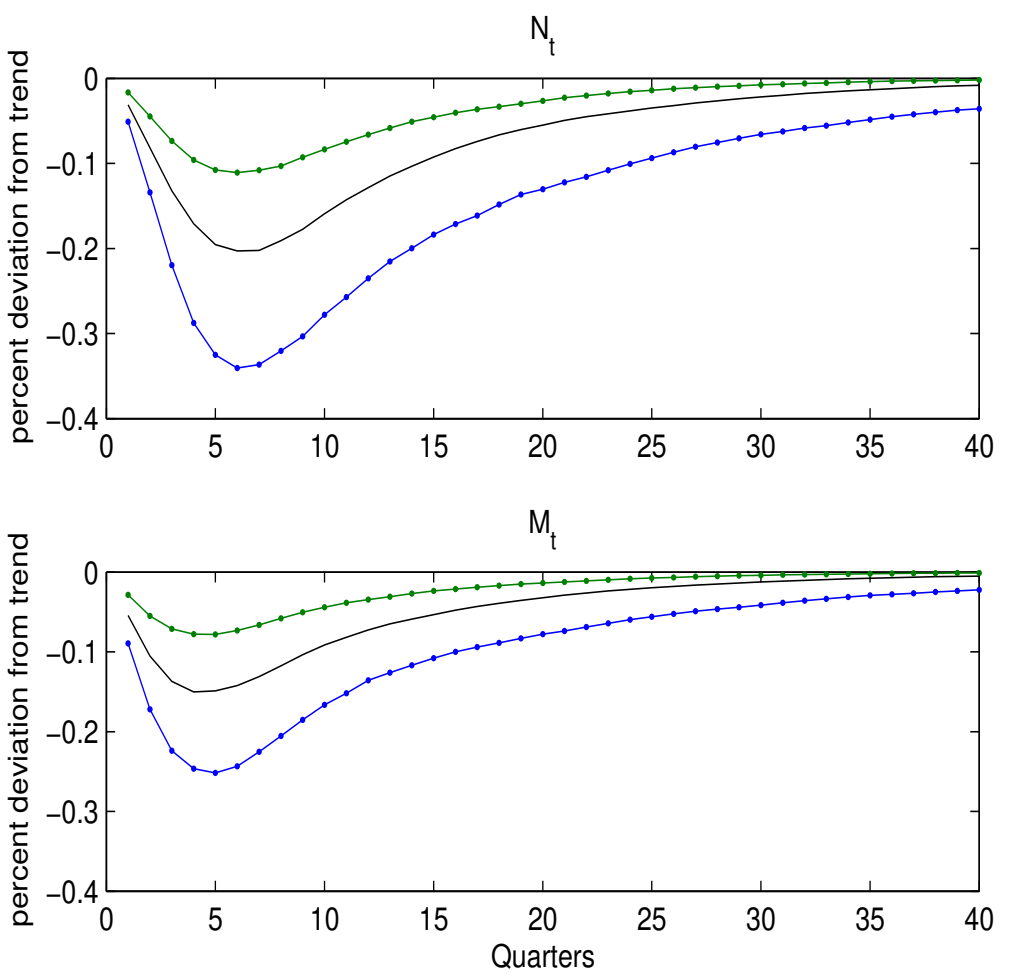
Table 3: Prior and Posterior distributions

\begin{tabular}{|c|c|c|c|c|c|c|c|c|c|}
\hline & \multicolumn{3}{|c|}{ Prior distribution } & \multicolumn{3}{|c|}{$\begin{array}{c}\mathcal{M}_{V A} \\
\text { Posterior distribution }\end{array}$} & \multicolumn{3}{|c|}{$\begin{array}{c}\mathcal{M}_{G P} \\
\text { Posterior distribution }\end{array}$} \\
\hline & Distr. & Mean & Std.dev. & Mean & $10 \%$ & $90 \%$ & Mean & $10 \%$ & $90 \%$ \\
\hline$\gamma$ & Gamma & 47 & 0.3 & 0.005 & 0.000 & 0.009 & n.a. & n.a. & n.a. \\
\hline$\gamma_{1}$ & Gamma & 47 & & n.a. & n.a. & n.a. & 0.038 & 0.004 & 0.070 \\
\hline$\gamma_{2}$ & Gamma & & 0.3 & n.a. & n.a. & n.a. & 1.432 & 0.837 & 2.007 \\
\hline$-\gamma_{3}$ & Gam & & & n.a. & n.a. & n.a. & & .000 & .001 \\
\hline$\gamma_{4}$ & Gam & & & 012 & 0.000 & 0.023 & & 007 & .154 \\
\hline$\phi$ & Gamma & 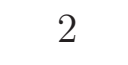 & & 438 & 2.112 & 2.769 & 120.867 & 87.905 & 153.186 \\
\hline$\varphi$ & Gan & 2 & & 66 & 3.081 & 5 & & 0.782 & 1.581 \\
\hline$\tau$ & Gamma & 0. & & 715 & 0.544 & 0.8 & & 0.002 & 0.057 \\
\hline$\theta$ & Gamma & & & 25 & 0.598 & & & 0.523 & 0.994 \\
\hline$\alpha$ & Gamma & 1.37 & & 205 & 0.984 & 1.416 & & 243 & 1.740 \\
\hline$\delta$ & Gamı & & & 92 & 0.365 & 0.6 & 9 & 74 & .563 \\
\hline$\rho_{x}$ & $\mathrm{Be}$ & 0 & & 0.762 & 0.719 & & & 00 & .903 \\
\hline$\rho_{w}$ & B & 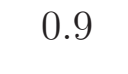 & & 28 & 0.893 & & & 3 & 0.964 \\
\hline$\rho_{v}$ & Beta & 0.9 & 0.05 & 0.956 & 0.931 & 0.982 & 18 & 920 & 0.977 \\
\hline$\rho_{r}$ & Beta & & & 14 & 0.870 & & & 2 & 0.902 \\
\hline$\rho_{y}$ & Uniform on & & 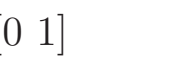 & 0.239 & 0.092 & 0.392 & 8 & .552 & 0.891 \\
\hline$\rho_{m}$ & Uniform on & & {$\left[\begin{array}{ll}0 & 1\end{array}\right]$} & 77 & 0.792 & 0.9 & 0.299 & 0.158 & 0.442 \\
\hline$\rho_{n}$ & Uniform on & & 1] & 0.237 & 0.002 & 0.414 & n.a. & n.a. & n.a. \\
\hline$\sigma_{m}$ & inv. Gamma & 0.05 & $2^{*}$ & 0.011 & 0.008 & 0.014 & 0.021 & 0.012 & 0.030 \\
\hline$\sigma_{n}$ & inv. Gamma & 0.08 & $2^{*}$ & 0.016 & 0.012 & 0.019 & 0.055 & 0.032 & 0.077 \\
\hline$\sigma_{y}$ & Uniform on & & 1] & 0.164 & 0.124 & 0.203 & 0.251 & 0.113 & 0.385 \\
\hline$\sigma_{x}$ & inv. Gamma & 0.03 & $2^{*}$ & 0.035 & 0.031 & 0.038 & 0.033 & 0.031 & 0.037 \\
\hline$\sigma_{w}$ & inv. Gamma & 0.02 & $2^{*}$ & 0.018 & 0.016 & 0.020 & 0.018 & 0.016 & 0.020 \\
\hline$\sigma_{v}$ & inv. Gamma & 0.03 & $2^{*}$ & 0.029 & 0.026 & 0.032 & 0.029 & 0.026 & 0.032 \\
\hline$\sigma_{r}$ & iv. Gamma & 0.015 & 2 & 0.017 & 0.015 & 0.018 & 0.017 & 0.016 & 0.019 \\
\hline
\end{tabular}

Notes. Posterior distributions are obtained using the Metropolis-Hastings algorithm with 400,000 draws. For the Inverse Gamma distribution the degrees of freedom are reported. The prior distribution for $\phi$ in the $\mathcal{M}_{G P}$ model is Gamma with a mean of 58 and std.dev. of 15 . 


\begin{tabular}{|c|c|c|c|c|c|c|c|}
\hline Quarters ahead & $\begin{array}{c}\text { Holding } \\
\text { cost (input) } \\
\text { shock }\end{array}$ & $\begin{array}{c}\text { Holding } \\
\text { cost (output) } \\
\text { shock }\end{array}$ & $\begin{array}{l}\text { Interest } \\
\text { rate } \\
\text { shock }\end{array}$ & $\begin{array}{c}\text { Materials } \\
\text { price } \\
\text { shock }\end{array}$ & $\begin{array}{l}\text { Wage } \\
\text { shock }\end{array}$ & $\begin{array}{l}\text { Sales } \\
\text { shock }\end{array}$ & $\begin{array}{c}\text { Technology } \\
\text { shock }\end{array}$ \\
\hline & \multicolumn{7}{|c|}{ Input } \\
\hline 1 & 20.3 & 14.9 & 0.13 & 4.9 & 0.0 & 3.9 & 55.9 \\
\hline 4 & 32.9 & 5.5 & 0.55 & 3.1 & 0.0 & 4.6 & 53.3 \\
\hline 8 & 40.4 & 4.0 & 0.94 & 2.3 & 0.0 & 11.9 & 40.4 \\
\hline 12 & 42.9 & 3.7 & 1.1 & 2.2 & 0.0 & 12.5 & 37.6 \\
\hline 20 & 44.2 & 3.6 & 1.2 & 2.1 & 0.0 & 12.2 & 36.6 \\
\hline 40 & 44.3 & 3.6 & 1.2 & 2.1 & 0.0 & 12.2 & 36.5 \\
\hline \multirow[t]{2}{*}{$\infty$} & 44.3 & 3.6 & 1.2 & 2.1 & 0.0 & 12.2 & 36.5 \\
\hline & \multicolumn{7}{|c|}{ Output } \\
\hline 1 & 5.6 & 36.1 & 0.0 & 2.6 & 0.0 & 29.3 & 26.3 \\
\hline 4 & 2.8 & 14.2 & 0.5 & 4.1 & 0.0 & 14.9 & 63.6 \\
\hline 8 & 2.3 & 11.3 & 1.3 & 3.8 & 0.0 & 16.0 & 65.4 \\
\hline 12 & 2.2 & 10.8 & 1.7 & 3.6 & 0.0 & 19.2 & 62.4 \\
\hline 20 & 2.3 & 10.6 & 2.1 & 3.6 & 0.0 & 19.6 & 61.7 \\
\hline 40 & 2.3 & 10.6 & 2.2 & 3.6 & 0.0 & 19.6 & 61.7 \\
\hline$\infty$ & 2.3 & 10.6 & 2.2 & 3.6 & 0.0 & 19.6 & 61.7 \\
\hline
\end{tabular}


Figure 2: One unit std.dev sales shock
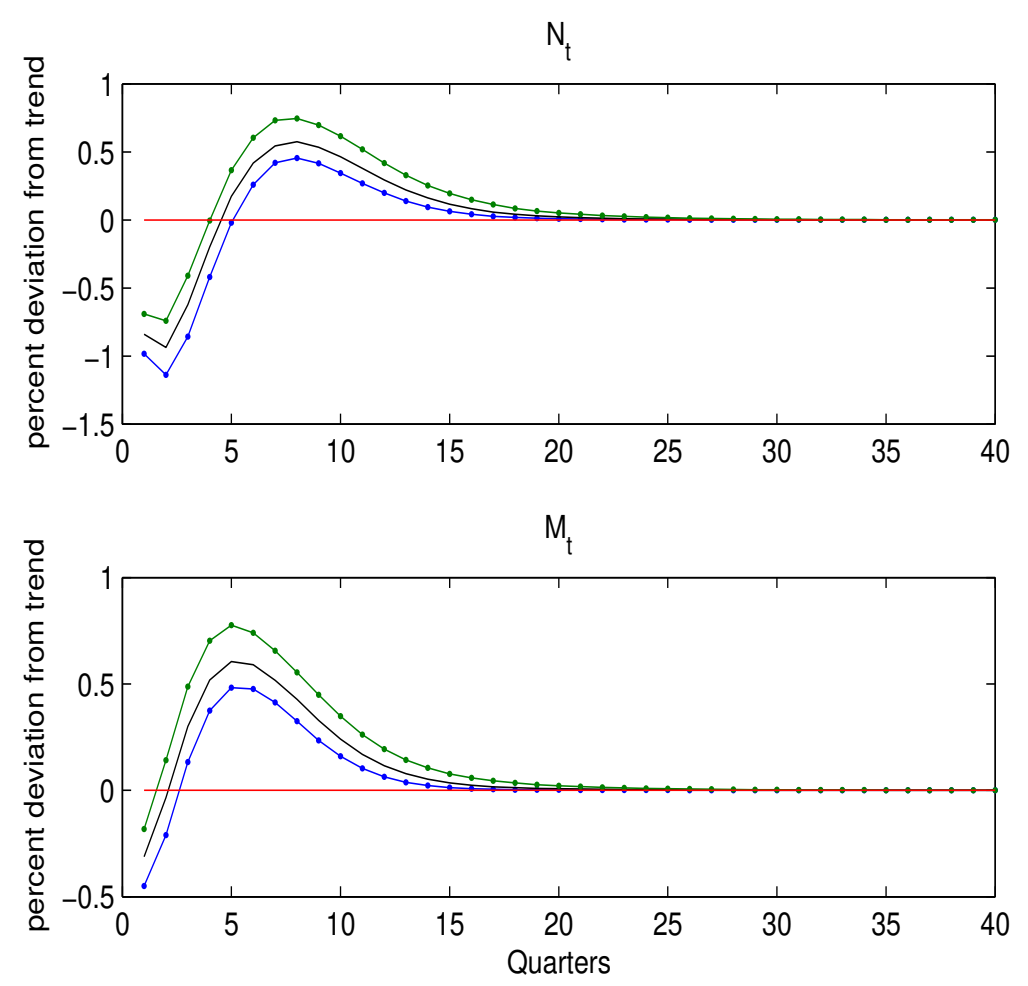

Figure 3: One unit std.dev technology shock
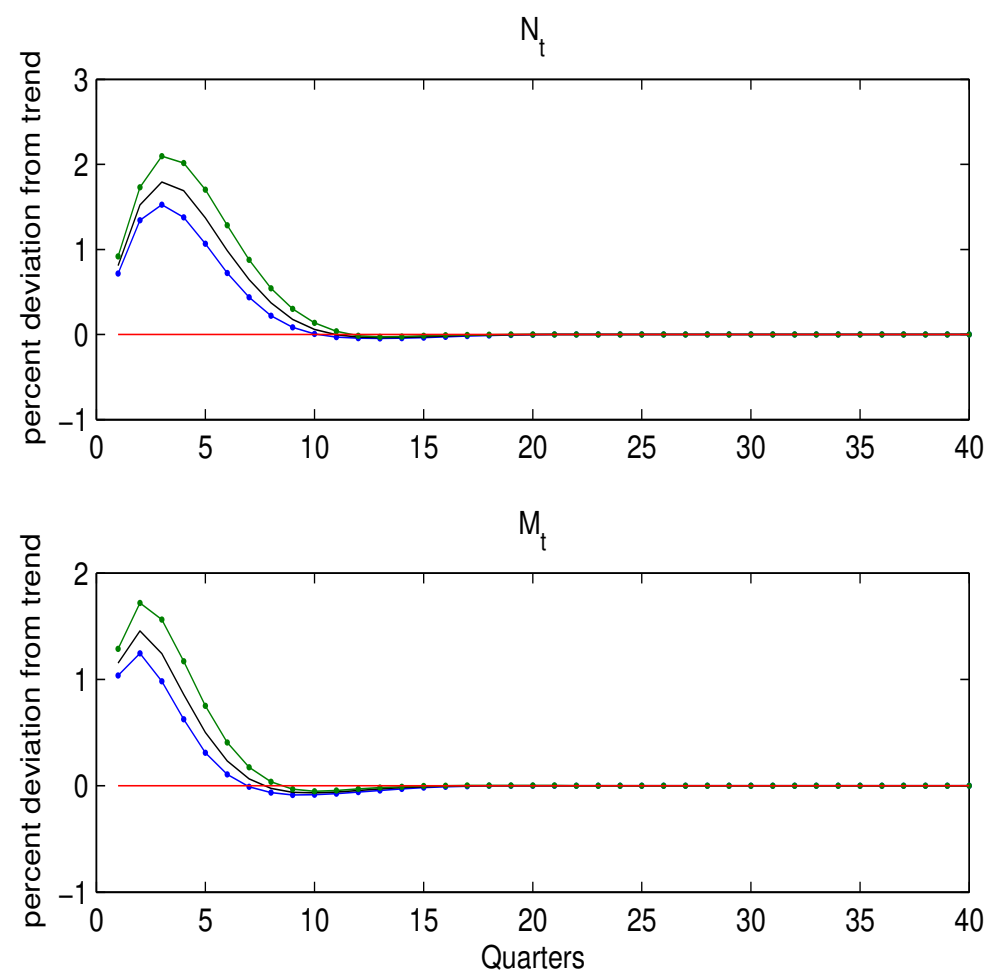